\title{
Evaluation of seismic hazard for the assessment of historical elements at risk: description of input and selection of intensity measures
}

John Douglas ${ }^{1}$, Darius M. Seyedi ${ }^{4}$, Thomas Ulrich ${ }^{1}$, Hormoz Modaressi ${ }^{4}$, Evelyne Foerster ${ }^{1}$, Kyriazis Pitilakis ${ }^{2}$, Dimitris Pitilakis ${ }^{2}$, Anna Karatzetzou ${ }^{2}$, George Gazetas ${ }^{3}$, Evangelia Garini ${ }^{3}$ and Marianna Loli ${ }^{3}$

${ }^{1}$ : BRGM, Orléans, France,j.douglas@brgm.fr.

${ }^{2}$ : Aristotle University of Thessaloniki, Thessaloniki, Greece.

${ }^{3}$ : National Technical University of Athens, Athens, Greece.

${ }^{4}$ : Formerly at: BRGM, Orléans, France.

Abstract The assessment of historical elements at risk from earthquake loading presents a number of differences from the seismic evaluation of modern structures, for design or retrofitting purposes, which is covered by existing building codes, and for the development of fragility curves, procedures for which have been extensively developed in the past decade. This article briefly discusses: the hazard framework for historical assets, including a consideration of the appropriate return period to be used for such elements at risk; the intensity measures that could be used to describe earthquake shaking for the analysis of historical assets; and available approaches for their assessment. We then discuss various unique aspects of historical assets that mean the characterisation of earthquake loading must be different from that for modern structures. For example, historical buildings are often composed of heterogeneous materials (e.g. old masonry) and they are sometimes located where strong local site effects occur due to: steep topography (e.g. hilltops), basin effects or foundations built on the remains of previous structures. Standard seismic hazard assessment undertaken for modern structures and the majority of sites is generally not appropriate. Within the PERPETUATE project performance-based assessments, using nonlinear static and dynamic analyses for the evaluation of structural response of historical assets, were undertaken. The steps outlined in this article are important for input to these assessments.

Keywords Seismic hazard assessment, site effects, intensity measures, fragility curves, historical buildings, cultural heritage assets, monuments

\section{Introduction}

As for modern structures, an evaluation of the seismic vulnerability of historical elements at risk ${ }^{1}$ requires that earthquake loading be defined in an appropriate manner. Historical assets are generally greatly different from the type of structures covered by current seismic design codes (e.g. Eurocode 8 , EC8) and they present great intra-group variation. Therefore, it is necessary to carefully consider what description(s) of earthquake loading needs to be considered for which type of historical asset. The hazard framework (e.g. in terms of return periods and deterministic or probabilistic approaches) prescribed in current design codes may not be appropriate for historical assets. This is because of, for example: their cultural and artistic importance and the acceptable level of retrofitting and strengthening considering archaeological and architectural constraints. The purpose of this article is to briefly summarise the assessment of hazard for historical assets. Because it is the only article in this special issue specifically covering hazard assessment it seeks to provide a background for those

\footnotetext{
${ }^{1}$ This article (and the PERPETUATE project) concerns historical buildings, such as those found in the centres of many towns in Europe, monuments (e.g. statues) and building contents (e.g. art works). In the following we use the general term 'historical assets' to mean all these types of elements at risk.
} 
readers not familiar with the state of the art in this field and for reference purposes for other articles in this volume.

The following section discusses the hazard framework used for historical assets within performancebased assessments. Hazard is commonly assessed in terms of intensity measures (IMs, also called strong-/ground-motion parameters) - a brief overview of the most common IMs and their estimation is given in the subsequent section. Section 4 is based on the classification of historical assets proposed in the PERPETUATE project (Lagomarsino et al., 2010; Lagomarsino et al., 2011; Lagomarsino and Cattari, 2013) and discusses the descriptions of seismic hazard that need to be considered for assets falling into each class. Because of overlaps between the descriptions required for each class this section is generally structured in terms of characteristics of earthquake actions (i.e. concerning the hazard) rather than in terms of asset classes (i.e. concerning the vulnerability/exposure). This is done by contrasting the requirements for the evaluation of historical assets to the requirements for modern elements at risk.

\section{Appropriate hazard framework for historical assets}

The current practice of selecting the appropriate seismic load with a given probability of exceedance (e.g. 10\%) in a certain period of time (e.g. 50 years) is not generally appropriate for historical assets. Checking a structure with this principle may lead to the requirement to undertake substantial retrofitting and strengthening, which could change its appearance and, consequently, its archaeological, architectural, historical and artistic value. Many historical monuments are already damaged and in many cases it is better to design retrofitting measures accepting a controllable degree of damage, respecting mainly the serviceability and usability of the asset (perhaps simply preventing collapse). On the other hand, historic buildings that are still in permanent use and occupancy (e.g. historical city centres) should have the same level of safety as modern structures, which means that their seismic resistance should follow the same principles as modern structures as defined by building codes. Furthermore, for historical town centres, the spatial correlation of ground-motion fields and the cross correlation of different scenarios must be taken into account. This is generally done by stochastically simulating sets of earthquakes (Goda and Atkinson, 2009; Jayaram and Baker, 2009). This procedure is still being developed and, hence, it is not discussed further. The hazard framework should cover both types of structures with respect to their usability, i.e. monuments with no or limited occupancy and historic buildings with permanent use and occupancy.

Hazard levels are associated with predefined probabilities of exceedance in a reference interval (e.g. $10 \%$ in 50 years) or, equivalently, predefined return periods (e.g. 475 years). Moreover, the seismic hazard is associated with the reliability of existing buildings. Hazard levels thus defined are then further modified through a coefficient depending on the importance of the building considered. In particular, importance is mainly related to the requirement that the structure remains operational after an earthquake.

By relating required performance targets and hazard levels, four considered return periods $\left(T_{R}\right)$ are proposed for each type of asset (Figure 1, Lagomarsino and Cattari, 2013). To take into account the varying importance and significance of each asset, the use of the following three values, to modify the return periods, is proposed: Use coefficient $\left(\gamma_{\mathrm{U}}\right)$, Building coefficient $\left(\gamma_{\mathrm{B}}\right)$ and Artistic coefficient $\left(\gamma_{\mathrm{A}}\right)$. These factors are defined as a function of the building use, its cultural and historical value and the presence of relevant artistic assets in the building (Lagomarsino and Cattari, 2013). Three independent coefficients are required because of the great variety of cultural heritage assets. Some highly important structures, from the historical and architectural point of view, are rarely used. In this case, it is 
necessary to prevent collapse, while life safety and immediate occupancy are not priorities. On the contrary, less important architectonic structures may be strategic or public buildings, for which use and safety performance are fundamental. Moreover, sometimes artistic assets are located in buildings that present no particular relevance from the architectural point of view; in these cases, the artistic coefficient can increase the seismic hazard for the verification of the artistic assets performance.

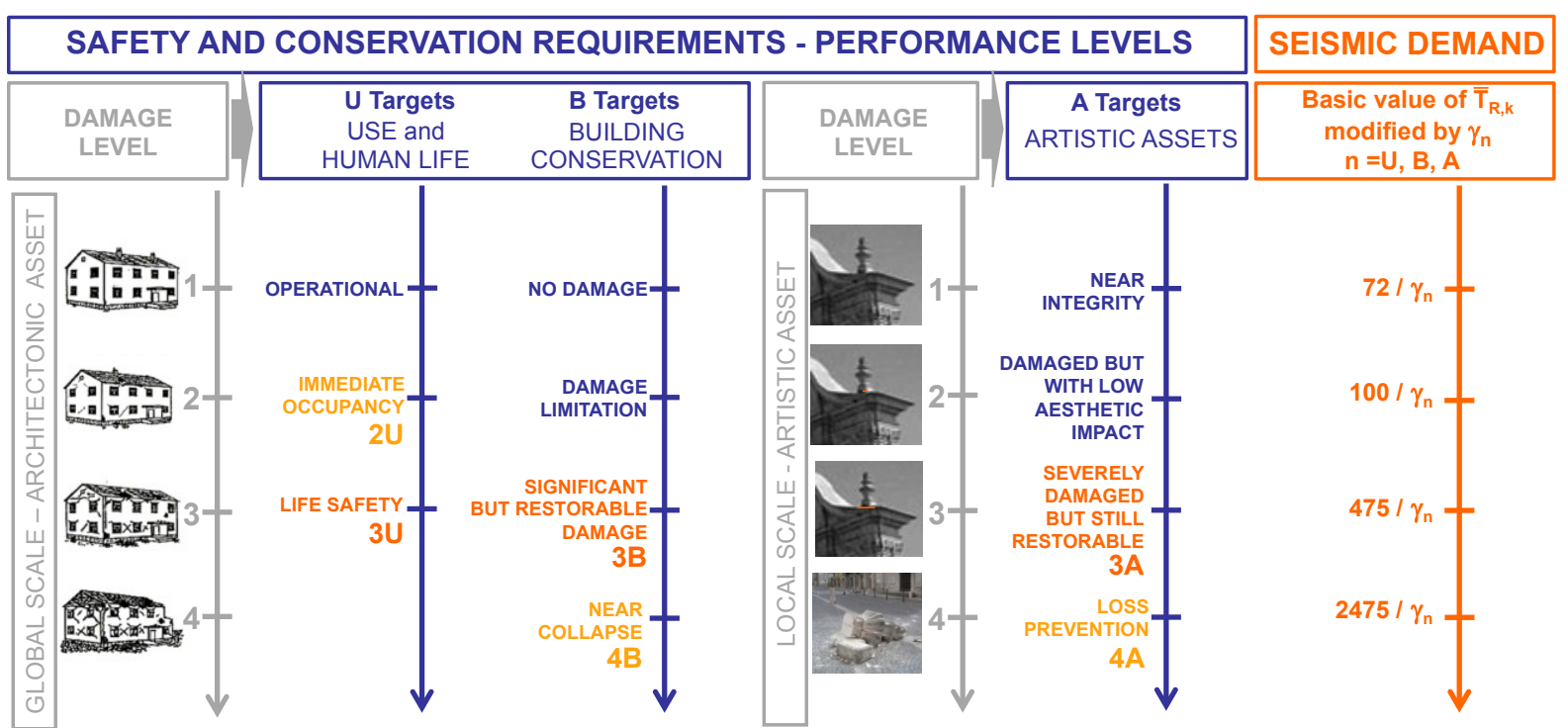

Fig. 1 Damage levels, performances and related return periods in years (Lagomarsino and Cattari, 2013).

These coefficients can be lower than unity when a particular performance is considered less important than average. In general, these coefficients can range from 0.5 to 2.0. Table 1 shows the return periods and the corresponding probability of exceedance in the reference period of 50 years associated to the different hazard levels. It is worth noting that $\mathrm{H} 1$ is very rarely considered for historical assets.

Table 1 Return periods in years (upper values) and probability of exceedance in 50 years (lower values) to be considered for the different earthquake hazard levels, as a function of the importance and significance coefficient (Lagomarsino and Cattari, 2013).

\begin{tabular}{|c|c|c|c|c|c|c|}
\hline & \multicolumn{5}{|c|}{ Importance and significance coefficient } \\
\hline & & 0.5 & 0.7 & 1 & 1.5 & 2 \\
\hline \multirow{4}{*}{ 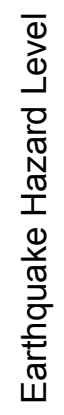 } & $\mathrm{H} 1$ & $\begin{array}{c}25 \\
86 \%\end{array}$ & $\begin{array}{c}35 \\
76 \%\end{array}$ & $\begin{array}{c}50 \\
63 \%\end{array}$ & $\begin{array}{c}75 \\
49 \%\end{array}$ & $\begin{array}{l}100 \\
39 \%\end{array}$ \\
\hline & $\mathrm{H} 2$ & $\begin{array}{c}36 \\
75 \%\end{array}$ & $\begin{array}{c}50 \\
63 \%\end{array}$ & $\begin{array}{c}72 \\
50 \%\end{array}$ & $\begin{array}{l}108 \\
37 \%\end{array}$ & $\begin{array}{l}144 \\
29 \%\end{array}$ \\
\hline & $\mathrm{H} 3$ & $\begin{array}{l}238 \\
19 \%\end{array}$ & $\begin{array}{l}333 \\
14 \%\end{array}$ & $\begin{array}{l}475 \\
10 \%\end{array}$ & $\begin{array}{c}713 \\
7 \%\end{array}$ & $\begin{array}{c}950 \\
5 \%\end{array}$ \\
\hline & $\mathrm{H} 4$ & $\begin{array}{c}1238 \\
4 \%\end{array}$ & $\begin{array}{l}1733 \\
2.8 \%\end{array}$ & $\begin{array}{c}2475, \\
2 \%\end{array}$ & $\begin{array}{l}3713 \\
1.3 \%\end{array}$ & $\begin{array}{c}4950 \\
1 \%\end{array}$ \\
\hline
\end{tabular}

\section{IMs for historical assets}

The assessment of seismic hazard for a given site is often performed for one (or more) IMs, which seek to characterise earthquake ground motions as a single (or multiple) scalar value(s). Since earthquake shaking is a complex non-stationary (both in the time and frequency domains) 
phenomenon, its characterisation as a single number is obviously a great simplification. This simplification, however, makes seismic hazard assessment much more straightforward since the link between earthquake (event) parameters, such as magnitude and location, and site parameters can be expressed as a closed-form equation [ground-motion prediction equations (GMPE), also known as attenuation relations] to estimate the probability of exceeding a given level of earthquake shaking. These probabilities are a vital input to probabilistic seismic hazard assessment (PSHA). The connection back to contributing earthquakes can be made through disaggregation of: PSHA results (e.g. Bazzurro and Cornell, 1999) or macroseismic intensity observations (e.g. Pace et al., 2011), to obtain the magnitude and distance of the most important scenarios and, thereafter, to choose appropriate accelerograms from a databank or simulate ground motions consistent with these scenarios. There are many techniques for the simulation of earthquake ground motions (see, e.g., Douglas and Aochi, 2008, for a review) but such techniques cannot be currently used within PSHA without passing through the step of assessing the probability of exceeding a given level of a certain IM. Therefore, IMs are fundamental within seismic hazard assessment and the definition of earthquake scenarios.

\subsection{Previously proposed IMs}

Many dozens of IMs have been proposed in the literature to capture different aspects of earthquake shaking, e.g.: amplitude, duration, frequency content, energy content and shape, or various combinations of these characteristics. The most commonly-used IMs are introduced below.

The IMs that are most often used to characterise earthquake shaking are: peak ground acceleration (PGA, the maximum absolute ground acceleration), peak ground velocity (PGV, the maximum absolute ground velocity), peak ground displacement (PGD, the maximum absolute ground displacement) and response spectral ordinates for a linear-elastic lightly-damped (often 5\% of critical) single-degree-of-freedom (SDOF) system. 'Response spectral ordinate' usually refers to spectral acceleration (SA, or pseudo-spectral acceleration, PSA), which is the maximum absolute acceleration that the mass of the SDOF system experiences during the earthquake shaking. Spectral displacement (SD), defined as the maximum absolute relative displacement experienced by the mass during the shaking, is, however, becoming increasingly employed due to the advent of displacement-based design (e.g. Priestley et al., 2007). Response spectral velocity (SV, or pseudo-spectral velocity, PSV), the maximum absolute relative velocity experienced by the mass during the shaking, is rarely used in earthquake engineering because it is difficult to relate to design parameters. PSV is, however, used to plot response spectra using the tripartite representation, where PSA, PSV and SD are all shown on a single graph using special logarithmic axes. These different response spectral measures (SA, SV and SD) are all highly correlated, except at very short and long periods, and PSA and PSV equal SD multiplied by $(2 \pi / T)^{n}$, where $n=1$ for PSV and 2 for PSA and T is the natural period of the SDOF system. Response spectra provide a convenient means of summarizing the peak response of all possible linear SDOF systems to a particular component of ground motion.

Response spectral ordinates can also be defined for different types of SDOF systems, such as those with elastic-perfectly plastic force-deformation properties, which can be defined in terms of constant strength or constant ductility. Other force-deformation functions (e.g. strain hardening and strain softening) are also sometimes used. Inelastic spectral ordinates are often estimated from elastic spectral ordinates by conversion formulae (e.g. Miranda and Bertero, 1994).

Standard response spectra in terms of SA and SD can be used to estimate the forces and deformations that a given structure will be subjected to during shaking. Some researchers consider the maximum 
absolute energy input into the system (e.g. Chapman, 1999). This property can also be plotted in terms of spectra for different periods and damping. These IMs remain, however, solely a research topic because of the difficulty of relating them to structural damage.

Spectral IMs defined in terms of systems with different periods, such as those described above, provide information on the frequency content of the earthquake shaking, which is important because structures have natural periods varying from a few tenths of a second (single-story building) to a few seconds (mainly Class $\mathrm{C}$ in the PERPETUATE classification, e.g. tall towers) and, therefore, they will feel the shaking differently. There are many IMs, however, that do not explicitly account for frequency content. The most obvious of these is PGA, although this equals SA and PSA for an infinitely-stiff structure $(T=0 \mathrm{~s})$ and it is strongly correlated to short-period (roughly $<0.2 \mathrm{~s}$ ) SA and PSA. To capture the frequency content of ground motions in terms of a single IM many versions of the spectral intensity (Housner, 1959), based on the integral of spectral ordinates over a given period range, have been proposed.

Response spectra (or other types of spectra, e.g. Fourier amplitude) provide a good representation of the frequency content of earthquake ground motions. For some engineering applications, however, it is useful to capture the predominant period (or frequency) of ground motions in a single number. Rathje et al. (2004) review different measures of the frequency content of ground motions, namely: mean period, defined in terms of the Fourier amplitude spectrum; predominant spectral period, defined as the period of the maximum spectral acceleration; smoothed predominant spectral period; and average spectral period. They conclude that the mean period is the most appropriate measure of the frequency content of the four IMs studied.

Although spectral energy parameters are not often computed, one IM that is related to the energy content of ground motion and which is quite commonly used is Arias (1970) intensity (AI), equal to the integral of the ground acceleration squared multiplied by $\pi / 2 \mathrm{~g}$. A number of related IMs measuring the duration, amplitude and energy-input rate can be defined based on AI. Apart from those related to the duration (discussed below) the other IMs derived from AI are not often used and, therefore, are not detailed here. A similar IM to AI is cumulative absolute velocity, which is computed using the integral of the absolute ground acceleration (sometimes only considering amplitudes over a certain threshold).

Many methods to characterise the duration of earthquake shaking have been proposed (Bommer and Martinez-Pereira, 1999). These are either absolute (defined in terms of absolute thresholds of acceleration or $\mathrm{AI}$ ) or relative (defined in terms of thresholds relative to the PGA or $\mathrm{AI}$ ) and are either bracketed (interval between first and last exceedance of an acceleration threshold), uniform (total length of time that absolute acceleration is above a threshold) or significant (interval between two thresholds of AI). These various quantities seek to capture different aspects of the duration of shaking and they often lead to greatly different values for the same accelerogram.

Earthquake ground motion features many cycles of motion that can have a damaging effect on structures. However, since the cycles are highly inhomogeneous in terms of frequency, amplitude and form there have been many proposals on how to count the number of effective cycles in a given strong-motion record. Hancock and Bommer (2005) review the various methods (both absolute and relative), including methods based on: rainflow counting, which counts both high- and low-frequency cycles in broad-banded signals, and peak counting, including or excluding non-zero crossings.

For systems whose deformation involves restoring mechanisms of elastic linear nature, the viscoelastic response spectra provide an efficient indication of an accelerogram's destructiveness. However, for systems with strongly inelastic restoring mechanisms, elastic spectra are often inadequate IMs. This is 
definitely the case with systems that rely solely on friction. The potential of a particular ground accelerogram to inflict damage to such systems has been investigated by Garini and Gazetas (2013), who studied two sliding systems (a rigid block on top of a horizontal or an inclined base) representing a symmetric and an asymmetric rigid-plastic restoring-force-displacement mechanism. With the supporting base of each system subjected to near-fault ground motions, the resulting slippage serves as an index of the damage that this motion can inflict on the system.

The use of IMs to characterise ground motions has advantages over using accelerograms (e.g. derived from the earthquake scenario) directly. Because of the infinite variety of possible earthquake ground motions it is easier to understand the results of the structural modelling if these motions are characterised by a small set of IMs. One IM (or a set of IMs) can then be used to evaluate the seismic risk via fragility functions. This simplification comes at the cost of introducing uncontrolled factors because the earthquake shaking cannot be fully characterised by only a few scalar parameters.

\subsection{Ground-motion models for prediction of IMs}

As noted above the availability of robust GMPEs for the prediction of the median value of an IM and its variability (generally modelled by the standard deviation, $\sigma$ ) is necessary for PSHA. If a GMPE is not available, the IM would have to be assessed through correlations with IMs that are themselves predictable from GMPEs or from accelerograms for disaggregated earthquake scenarios.

The ubiquitous use of PGA and elastic response spectra is demonstrated by the large number of published GMPEs for these IMs [Douglas (2011) identifies more than 200 models] for many types of earthquakes (e.g. shallow crustal, stable continental, subduction and mining-induced) and many regions. Therefore, for these parameters the problem is not a lack of GMPEs but which GMPEs to choose. Epistemic uncertainty in the prediction of earthquake ground motions remains high (e.g. Douglas, 2010) due to a lack of data (particularly in the near-source region) and knowledge on, for example, the appropriate independent parameters and functional form. Therefore, it is common practice to apply a number of GMPEs within PSHA and weight the results based on the degree of belief in a certain GMPE providing the correct estimate of the median ground motion and its variability (e.g. Delavaud et al., 2012).

Other IMs are less well served by robust GMPEs. Douglas (2012) identified 96 GMPEs for the prediction of PGV, 19 for PGD, 33 for $\mathrm{AI}$ and 15 for relative significant duration. There are even fewer published GMPEs for the remaining IMs (e.g. inelastic spectral ordinates, other measures of duration, number of cycles and fundamental periods), which means that their estimation could be problematic. For structures with large or long geographical footprints (e.g. city walls) an important IM could be the maximum transient ground strain. The prediction of this parameter is discussed by Paolucci and Smerzini (2008), who provide equations for its estimation based on correlations with PGA and PGV.

When conducting seismic hazard analyses for the prediction of more than one IM it is important to consider the correlations between the parameters otherwise the evaluated seismic hazard and scenarios will not correspond to the desired probability of exceedance. To take account of correlations, vectorvalued PSHA (e.g. Bazzurro and Cornell, 2002) has been proposed but is rarely conducted in practice.

GMPE should generally be reserved for the estimation of ground motions at stiff soil or rock sites; for soft soil site-specific analyses should be preferred (Baturay and Stewart, 2003). Site amplification factors given in codes (e.g. EC8 or NEHRP) could also be used to define earthquake loading for non- 
rock sites. Improved site amplification factors and site classification categories for EC 8 have been recently proposed by Pitilakis et al. (2012, 2013a, b).

\subsection{Selection of the most appropriate IMs for historical buildings}

Fragility functions are a key instrument in modern seismic risk assessments, such as undertaken in PERPETUATE (see other articles in this special issue). A fragility function provides the conditional probability that a considered asset equals or exceeds a certain damage level for a given level of earthquake loading, represented by an IM or a set of IMs. As mentioned before, each IM represents certain characteristics of the seismic action and, therefore, the choice of the appropriate IM depends on the structural behaviour of the studied asset (e.g., Seyedi et al., 2010; Gehl et al., 2013).

In the scope of seismic risk assessment of historical assets, it is important to select the IMs carefully to reduce scatter in the final results. Often the most appropriate IM will vary with the type of asset. This selection requires non-linear time-history analyses (unlike the capacity spectrum method). In this view, Gehl et al. (2013) developed a procedure that relies on the statistical treatment of numerous nonlinear dynamic analyses. At first, a structural model is considered and characterized within modal and pushover analysis to identify dynamic properties and damage limit states of the structure, respectively. The performance of each IM can then be evaluated based on calculation results using data mining techniques, such as: the variable clustering method, comparison of standard deviations of fragility functions and receiver-operating-characteristics analysis.

\section{Appropriate descriptions of earthquake actions}

Lagomarsino et al. (2011) provide a classification of cultural heritage assets by the type of damage that can occur during earthquakes. Seven main asset classes are defined: A) assets subjected to prevailing in-plane damage, B) assets subjected to prevailing out-of-plane damage, C) assets damaged by high combined axial and bending loads, D) arched structures subjected to in-plane damage, E) massive structures to which local failure of masonry prevails, F) blocky structures subjected to overturning and sliding and $\mathrm{G}$ ) built systems subjected to complex damage. The following discussions are based on these seven asset classes.

\subsection{Accounting for site effects}

Local site conditions influence strong ground motion in several ways, which are collectively referred to as site effects. These are related to the thickness and impedance contrast between soil layers, the surface and the subsurface topography (lateral discontinuities, faults, valley and basin edges, inclined soil layers or soil-bedrock interfaces) and soil non-linearity. Additional local effects may include liquefaction, lateral spreading and landslides, which are briefly discussed below.

At small strains soil behaves linearly and hence amplitude-independent site amplification factors are appropriate. However, at greater accelerations the soil stiffness degradation and nonlinearity reduce substantially the amplitude of the propagating seismic waves resulting in significant attenuation of the surface motion in comparison to the bedrock excitation. This reduction in acceleration is accompanied by irreversible soil displacement. The reader is referred to Pitilakis (2004) for a review.

During earthquakes, the amplitude, frequency content and duration of shaking change as seismic waves propagate through soil layers and reach the surface. This phenomenon, wherein the local soil acts as a filter and modifies the ground motion characteristics, is known as site response. When shear waves reach boundaries between different soil materials, they are reflected, refracted and converted 
resulting in amplification or attenuation of motion. Under the idealisation of linear-elastic conditions, the amplification/attenuation depends only on the relation of the natural frequency of the soil (its depth and stiffness) to the frequency content of the excitation. However, reality is often more complicated and unpredictable behaviour can take place because of nonlinear material behaviour, resulting in the generation of higher-frequency waves and a decrease of its natural frequencies.

Soil layer effects have been investigated extensively, and much of the present knowledge is reflected in modern seismic codes. The current understanding of site effects is that the first and most important factor explaining the observed response is the impedance contrast and secondly the trapping of upgoing seismic waves. For example, EC8 and other seismic codes propose amplification factors and response spectral shapes for specific soil categories, based essentially on the amplification produced by the thickness and the impedance contrast between soil layers. Basin edge, valley and lateral irregularity effects are not yet fully understood and they have not yet been introduced into building codes as they are more difficult to understand and quantify in a simple manner.

A scalar factor, which alone accounts for the amplification of ground motion and its spatial distribution, is insufficient. Modelling based on a one-dimensional approximation fails to reproduce the long duration of strong motion, in particular in deep and large basins. This type of induced ground motions could particularly affect long-period structures (e.g., building class C) or components. It is not always valid to separate source and path effects from site effects. The latter is dependent on the first two factors. This important fact will be demonstrated in the following sections discussing valley and topographic effects as well as other aspects of ground motion.

The analysis of site effects on ground motion presupposes detailed and well-focussed geotechnical and geological surveys including specialized laboratory and field tests. These surveys are even more important when soil-foundation-structure effects are taken into consideration.

\subsubsection{Accounting for valley and basin effects}

The effects of subsurface geometry (e.g. valley and basin edges and lateral discontinuities) on ground motion have been recognized for a long time and have been the topic of several instrumental and many theoretical and numerical investigations in the past decades. The complexity of these phenomena, combined with the limitations of both geophysical and geotechnical measurements and numerical simulations, have not yet made it possible to include such effects in standard seismic hazard assessments. Modern building codes, like EC8, do not include any prevision for basin edge and valley effects.

- Alluvial basins may strongly influence the nature and intensity of ground shaking. Conventional 1D modelling generally fails to reproduce the wave scattering phenomena introduced by the non-level geometry. Such phenomena include: (1) generation of surface waves (Rayleigh and Love) at the basinedge lateral boundaries, which tend to increase both the amplitude away from the edges and the duration of ground motion; (2) amplification and resonance enhanced by low-velocity non-horizontal near-surface layers; and (3) multiple refractions and reflections of incoming waves at the sloping boundaries and the ground surface ("entrapped" waves). All these phenomena are responsible not only for aggravating the ground motions but also for producing a potentially destructive "parasitic" vertical component (Gelagoti et al 2010). On the other hand, strongly nonlinear soil response tends to abate some of these adverse effects (Gelagoti et al 2012). Source, path, and azimuthal effects may also complicate the ground motions.

\subsubsection{Accounting for steep topography}


Historical city centres or monuments are often on the tops of steep hills because of defensive, cultural, agricultural or religious reasons. It has been found that steep topography can significantly amplify ground motions at certain frequencies and distances from the relief edge. Therefore, this should be accounted for when assessing ground motions at such sites. Formulations in seismic design codes on topographic amplification are unlikely to be sufficient because the slopes at the sites of historical structures are sometimes steeper than those covered by such recommendations. For example, based on ground-motion observations from aftershocks of the L'Aquila 2009 earthquake recorded at two sites, Gallipoli et al. (2013) find that the Italian code previsions for the topographic amplification factor underestimated the observed amplifications. EC8 incorporates an aggravation factor to the design acceleration depending only on the geometry of the surface topographic relief. There are no provisions accounting for the presence of lateral discontinuities or the spatial variation in the deposit thickness. The incidence angle and the frequency content of the induced wave field are currently ignored. Also, no discrimination is made as to whether the site is a slope or a hill, i.e. whether the ground behind the slope is at the same level. Moreover the ground (geological and geotechnical) conditions do not play any role in these code recommendations; the amplification is purely a geometrical effect.

342

\subsubsection{Accounting for specific site conditions}

Similarly to the situation for steep topography it is common to classify areas of very poor soils as "not fit for building unless specific soil improvement measures are taken'. However, these sites may already be the location of historical buildings (e.g. the Tower of Pisa). In addition, in some cities more recent historical structures are built on the debris of previous buildings and monuments, which may date from centuries before (e.g. this is typical in ancient cities like Rome, Naples and Thessaloniki). This means that the strong or peculiar amplifications that could occur at such sites need to be assessed. The guidance provided by design codes is likely to be totally insufficient for such sites since they are not a usual location for modern structures.

Monumental structures founded on very soft soil deposits or upon the debris of ancient cities may undergo excessive deformations in case of an earthquake because of nonlinear soil response. This may cause performance problems, especially for particularly heavy structures. Consequently, the effect of soil on the seismic response of monuments can only be studied through the comprehensive prism of soil-structure interaction.

Finally, while rare, there are several monuments that are founded above a strong geological and geotechnical discontinuity, which may produce serious damage to the structure even under static conditions. Examples include an ancient Greek temple in the Peloponnese, for which the discontinuity may be the surface trace of an active fault, and the Colosseum in Rome, which straddles two types of quaternary deposits.

\subsubsection{Accounting for soil-foundation-structure interaction}

Monumental buildings with masonry foundations are often characterized by massive and complex structural systems. During an earthquake, such systems might be prone to soil-foundation-structure interaction (SFSI), which could modify the response of the foundation. Kinematic SFSI may filter the energy transferred to the structure, and alter significantly its seismic response. It is well known that for heavy stiff structures resting on soft soil, linear and nonlinear SFSI play an important role on the response of the foundation (Pitilakis et. al, 2013c). SFSI transfers stress fields from the structure to the foundation, filtering high frequencies of the incoming seismic wave and thereby modifying the 
resonance period of the building (Pitilakis and Clouteau, 2010). This, in turn, influences the design of mitigation measures for the monument.

Conventional foundation models usually consider the foundation as a non-deformable rigid body. On the contrary, historical masonry buildings have a foundation system that can transfer negligible tensile stress and no bending moment. As a result, the response of flexible and brittle foundation systems cannot support significant rocking movement, considerably affecting the overall structural response. In this case, soil-foundation interaction should be accounted for by using models incorporating soilfoundation compliance and damping increases (Pitilakis and Karatzetzou, 2013).

Modern seismic codes are based on performance-based assessment, which often employ static pushover analyses for the evaluation of structural capacity. Traditionally, pushover analyses are performed assuming a structure that is fixed at its base. Foundation compliance and the geometry of the foundation system may, however, significantly modify the actual response in terms of both capacity and demand, resulting in altered seismic performance.

\subsection{Elastic approximation}

Modern seismic design codes often reduce the elastic forces computed from earthquake response spectra by a factor (often called $\mathrm{R}$ or $\mathrm{q}$ ) that accounts for inelastic behaviour of the structure under strong earthquake loading. According to $\mathrm{EC} 8$, the behaviour factor $\mathrm{q}$ is an approximation of the ratio of the seismic forces that the structure would experience if its response was completely elastic with $5 \%$ viscous damping, to the seismic forces that may be used in design, with a conventional elastic analysis model, still ensuring a satisfactory response of the structure. Moreover, the behaviour factor q accounts for the influence of the viscous damping being different from $5 \%$, which may also vary in different horizontal directions of the structure.

Despite the merits of this simplified approach, several drawbacks are encountered in practice. Since this reduction factor was initially conceived for systems assumed to have elastic-perfectly-plastic behaviour, its use requires that the plastic mechanisms that develop in the structure under investigation be of the same nature. However, this type of elastic-perfectly plastic material behaviour is not normally desired for historical buildings and monuments nor is it possible for massive masonry structures (class E). Historical buildings were not designed to sustain large plastic deformations, due to brittle failure of the construction materials used in the past. Moreover, the energy dissipation mechanism is different in historical buildings and monuments from modern structures, due to the different shape of the hysteresis loop, which also depends on the material. In such situations, the use of reduction factors with elastic spectra is inappropriate and elastic response spectral ordinates are more useful than inelastic quantities.

\subsection{Accounting for long-period motions}

Class C structures (e.g. towers) may have natural periods longer than 2s. Structures with out-of-plane mechanisms (class B) and blocky structures (class F) could also require accurate ground-motion estimates for periods longer than 2 s. Seismic codes have largely adopted smooth design acceleration spectra, which may be applicable up to a period limit of 2 to $4 \mathrm{~s}$. The response of monuments, some of which may respond strongly inelastically (towers, columns and other particularly slender structures) with periods significantly longer than $2 \mathrm{~s}$, also gives rise to the need for design response spectra that extend to longer periods than have been traditionally considered. This need is even more pronounced 
when the capacity spectrum method is applied, where the design demand spectra are strongly affected by limited knowledge of long-period ground motions.

Until recently the prediction of response spectral ordinates for periods longer than about $2 \mathrm{~s}$ was difficult because of a lack of reliable GMPEs beyond this period, due to low signal-to-noise ratios for records from analogue accelerograms particularly those from small earthquakes. However, the advent of digital strong-motion networks and improvements in accelerogram processing procedures means that robust GMPEs are now available to predict response spectral ordinates to $5 \mathrm{~s}$ and beyond, e.g. those produced in the Next Generation Attenuation (NGA) project (e.g. Abrahamson et al., 2008).

\subsection{When elastic response spectra are not adequate descriptors of hazard}

Class $\mathrm{F}$ and $\mathrm{G}$ assets, which include elements subjected to rocking or sliding, are strongly inelastic systems. The analysis of idealized systems corresponding to this type of asset (e.g. a rigid block rocking or sliding on a horizontal or sloping rigid base) shows that their response is extremely sensitive to the presence, characteristics, sequence and direction of long duration pulses (Garini et al, 2011). Hence, forward-directivity and fling-step affected motions, which contain severe acceleration pulses and/or velocity steps, may be particularly destructive for these systems. Sliding systems are governed by the Coulomb friction law defined by a single parameter (the friction coefficient, $\mu$ ), which allows the introduction of "equivalent" sliding motions for a given displacement level. In this type of analysis the block remains in full contact with its base while moving with the same acceleration and velocity, until the triggering acceleration exceeds the critical yield acceleration. The response of the block is fully inelastic once sliding starts. For the inclined system, the relative displacement between the block and the base prevails in the downward direction and, therefore, slippage accumulates in every sliding period and the block cannot end up in its initial position. In contrast for the horizontal case, sliding occurs in both directions and, therefore, the block can theoretically return to its origin (Gazetas et al, 2009).

Response spectra are not adequate descriptors of the purely plastic response of such systems. This has been demonstrated by employing the concept of "equivalent" response spectra, where equivalent means spectra (up or down-scaled versions of actual accelerograms), that have an identical effect on the (strongly) inelastic idealized systems - just overturning of the rocking block, or a certain amount of slippage of the sliding block (Gazetas, 2012). The resulting equivalent response spectra exhibit a huge scatter, even within each type of system, with the largest and smallest spectra differing by a factor of more than three, throughout the entire period range of interest. This type of analysis shows that the use of elastic spectra as a representative index of destructiveness for all systems is limited and it is necessary to use more appropriate IMs for certain asset classes.

\subsection{Accounting for earthquake loading in more than one direction}

Earthquake analysis of ordinary structures conducted within the framework of current seismic design codes does not account for shaking in more than one horizontal direction at a time, or if it does then this is often via simple rules. This is because modern structures in seismically-active regions are often designed to be roughly symmetrical to avoid torsion effects and because the predominant failure mode of modern structures is in-plane, for which earthquake shaking in the axis of the wall is the critical parameter. In addition, vertical earthquake shaking is not often accounted for, or again it is accounted by simple means, because modern buildings have a high factor of safety against gravity loads and long 
horizontal spans, for which vertical loads could be important, are not common. Certain types of historical buildings, however, may require careful consideration of all three components (two horizontal and one vertical) of earthquake ground motions. This is even more important when the two horizontal components have significantly different amplitudes, e.g. due to directivity near the earthquake source.

Structures categorised into asset classes B (those subjected to prevailing out-of-plane damage) and A (subject to torsion) would need both horizontal components of earthquake shaking to be considered. Structures categorised into asset classes $\mathrm{C}$ (those damaged by high combined axial and bending loads) and D (arched structures subjected to in-plane damage) would need a consideration of the vertical component of motion to be made. For class $C$ structures, this will contribute to the axial loads and will affect the bending loads, and, for class D structures, the vertical shaking will affect the vertical loads applied on the arch. Class F structures (blocky structures subjected to overturning) require a consideration of vertical motions since this loading could reduce the apparent weight of its elements and hence make them easier to overturn.

In many damaging earthquakes of the last twenty years, the vertical component was high relative to the horizontal. Moreover, even if certain components of the earthquake acceleration seem insignificant by themselves, they could increase the damage of the earthquake when they are combined with shaking in other directions. Thus, certain locations and buildings may require careful consideration of all three components of earthquake ground motions.

Historical buildings can present design (e.g. geometric or constitutive) weaknesses that could activate complex 3D failure modes such as torsional and high vibration modes, which are usually not considered in standard vulnerability assessments. Buildings that were not specifically designed under seismic risk mitigation rules often present combined eccentricities in term of mass, stiffness and strength. These weaknesses could be the source of significant damage, when the buildings are exposed to motions in two or three dimensions. For instance, if a building presenting strength eccentricity is exposed to large motions in both horizontal dimensions, a decrease in stiffness due to plastic deformations in the weak direction will probably substantially influence its behaviour in the orthogonal direction. The building cannot be realistically modelled by a $2 \mathrm{D}$ frame and, hence, a full 3D model must be used.

The consequences of simultaneous shaking in three directions to historical buildings can be increased because of other specificities shared by these buildings. The structural complexity of many of these buildings can notably increase their vulnerability: some 3D structures, such as vaults, can be seriously affected by $3 \mathrm{D}$ accelerations, which could involve the loss of equilibrium of the structure. Moreover, the weaknesses of some highly vulnerable historical buildings could be highlighted by such ground motion: cracks will form at the weak connections among walls, or among walls and floors resulting in blocks or in wall overturning.

\subsection{Accounting for permanent displacements}

Large magnitude earthquakes are often accompanied by permanent ground displacements at the surface because of large fault movements, even when the rupture is blind. This may induce significant distress to overlying structures. The mechanisms of fault-soil-structure interaction have been addressed in the literature through analysis of historical case studies (e.g. Anastasopoulos and Gazetas, 2007; Faccioli et al., 2008), small and large scale experiments (e.g. Loli et al., 2011) and nonlinear 
finite element analyses (e.g. Anastasopoulos et al., 2009). Furthermore, there have been recent attempts to estimate permanent displacement associated damage and develop fragility curves (e.g. Fotopoulou and Pitilakis, 2012, 2013; Negulescu and Foerster, 2010).

Massive large dimension structures categorized in asset class E cover large extended areas (e.g. defensive city walls). For this type of asset it is important that permanent ground displacements, such as those caused by proximity to the fault trace, seismically-induced landslides or on ground that liquefied, are accurately assessed so that strains and deformations in the structure can be estimated. For these situations the critical ground motions are not best described by (elastic) response spectra but with time histories containing: strong one-sided pulses, long-period motions and, ideally, including the permanent offset.

Unlike current buildings for which the seismic performance is usually expressed by the maximum instantaneous displacement (e.g. the inter-storey drift) and by the ductility demand associated with this displacement, for massive linear structures like the ones included in class D (e.g. triumphal arches, aqueducts and bridges) the seismic performance is generally expressed in terms of permanent displacements at the end of the earthquake. This class of structures undergoes permanent displacements in only one direction and therefore the displacements increase monotonically and reach a maximum at the end of the earthquake.

It is difficult to decide for which monument classes permanent displacement play an important role in the occurrence of damage since the classes are defined mainly considering characteristics of the upper structure while permanent displacements act at the foundation level. If the foundation system has the ability to accommodate large deformations or to span soft spots then the damage that a structure may suffer due to permanent displacement can be significantly reduced compared to a foundation system that does not possess any ductility. The majority of historical monuments have shallow foundation systems, but it is important to know if all foundation elements (perimeter and interior wall footings) are tied together to enable them to bridge areas of local settlement and provide better resistance against soil movements. The problem is that, unlike the upper structure, the foundation system cannot be evaluated only by visual inspection of the monument. Moreover, the foundation system can be very different from one monument to another even for structures belonging to the same class. Finally the integrity of the foundation system may be seriously affected by, for example, aging and non-rigidbody behaviour of the foundation. In this case the impedance functions used in the structural modelling should be modified from those for the infinite rigidity case. Impedance functions have recently been proposed for flexible masonry foundations by Pitilakis and Karatzetzou (2013).

The standard approach for the seismic design of shallow foundations is equivalent to ensuring that the bearing strength factor of safety does not fall below a certain value. However, brief instances of bearing failure (yielding) during an earthquake may not necessarily be destructive. A more important consideration is the residual foundation displacements accumulated at the end of the earthquake (Toh and Pender, 2008). This suggests that deformations caused by earthquakes can be developed in two consecutive steps (governed by the soil deformation): the first step during the earthquake can bring instability and generate a failure surface and the second step can follow immediately after the earthquake if the residual shear strength on the failure surface is less than the one required to maintain static equilibrium. In the first stage the damage of the structure is mostly due to the shaking while in the second stage it is caused by the soil deformation. A series of earthquakes of different intensities may also lead to accumulation of permanent deformations at the foundation level. 
Few studies can be found in the literature where the effect of permanent ground displacements has been addressed with regards to historic assets. Three recent articles can be cited: Karakhanian et al. (2008), concerning the St. Simeon Monastery (Syria); Galli and Galadini (2001), reporting several cases of surface faulting on archaeological relics in the Dead Sea Valley, Crete and central and northern Italy; and Oliveira (2003), modelling various Portuguese structures. A comprehensive numerical study on the effect of normal fault rupture interacting with masonry structures is presented in Gazetas et al. (2013), which demonstrates the key role of the foundation continuity and stiffness.

\section{Conclusions}

This paper is an introduction to seismic hazard assessment for the analysis of historical assets. It constitutes one of the principal steps of the performance-based assessments undertaken within the PERPETUATE project. After a brief discussion on the appropriate hazard framework, the IMs that could be used to describe earthquake shaking applied to historical assets were presented and available models for their assessment were introduced. The importance of the choice of appropriate IMs for each type of historical asset was emphasised. Based on the classification of historical assets proposed in PERPETUATE, about a dozen characteristics of historical assets or their locations were discussed with respect to their impact on how seismic hazard should be described. In particular, differences from the approaches described in building codes for modern buildings were highlighted. Specific aspects, such as, strong local site effects due to steep topography (e.g. hilltops), basin effects or foundations built on the remains from previous structures were presented. The suitability of elastic response spectra for different classes of historical assets was also discussed. The cases where more than one direction in the earthquake loading must be considered were identified. A decision tree approach could be useful for a preliminary screening of historical assets to identify critical aspects of the site and monument but because historical assets are often special cases such tools are not appropriate for detailed studies. What is required is expert analysis covering all relevant disciplines and not blind obedience to guidelines. The themes and concepts introduced here are developed further and applied to actual case studies in subsequent articles in this volume and also in PERPETUATE reports.

Acknowledgments The work presented in this article has been funded by the PERPETUATE (Performancebased approach to earthquake protection of cultural heritage in European and Mediterranean countries) project of the EC-Research Framework Programme FP7. We thank two anonymous reviewers and the guest editors Sergio Lagomarsino and Dina D'Ayala for their comments on a previous version of this article.

\section{References}

Abrahamson, N., Atkinson, G., Boore, D., Bozorgnia, Y., Campbell, K., Chiou, B., Idriss, I. M., Silva, W., Youngs, R. (2008), Comparisons of the NGA ground-motion relations, Earthquake Spectra, 24(1), 45-66.

Anastasopoulos, I., Gazetas, G. (2007), Foundation-structure systems over a rupturing normal fault: Part I. Observations after the Kocaeli 1999 Earthquake, Bulletin of Earthquake Engineering, 5(3), 253-275.

Anastasopoulos, I., Gazetas, G., Bransby, M. F., Davies, M. C. R., El Nahas, A. (2009), Normal fault rupture interaction with strip foundations, Journal of Geotechnical and Geoenvironmental Engineering, ASCE, 135(3), 359-370.

Arias, A. (1970), A measure of earthquake intensity. Pages 438-483 of: Hansen, R.J. (ed), Seismic Design for Nuclear Power Plants. The M.I.T. Press.

Baturay, M. B., Stewart, J. P. (2003), Uncertainty and bias in ground-motion estimates from ground response analyses, Bulletin of the Seismological Society of America, 93(5), 2025-2042. 

America, 89(2), 501-520.

Bazzurro, P., Cornell, C. A. (2002), Vector-valued probabilistic seismic hazard analysis (VPSHA), Proceedings of 7th U.S. National Conference on Earthquake Engineering, Boston, MA, July 21-25, Paper No. 61.

Bommer, J. J., Martinez-Pereira, A. (1999), The effective duration of earthquake strong motion. Journal of Earthquake Engineering, 3(2), 127-172.

Chapman, M. C. (1999), On the use of elastic input energy for seismic hazard analysis, Earthquake Spectra, 15(4), 607-635.

Delavaud, E., Cotton, F., Akkar, S., Scherbaum, F., Danciu, L., Beauval, C., Drouet, S., Douglas, J., Basili, R., Sandikkaya, M. A., Segou, M., Faccioli, E., Theodoulidis, N. (2012), Toward a ground-motion logic tree for probabilistic seismic hazard assessment in Europe, Journal of Seismology, 16(3), 451-473. DOI: 10.1007/s10950-012-9281-z.

Douglas, J. (2010), Consistency of ground-motion predictions from the past four decades, Bulletin of Earthquake Engineering, 8(6), 1515-1526, doi: 10.1007/s10518-010-9195-5.

Douglas, J. (2011), Ground-motion prediction equations 1964-2010, Final report, BRGM/RP-59356-FR (PEER 2011/102), 444 pages, 9 illustrations.

Douglas, J. (2012), Consistency of ground-motion predictions from the past four decades: Peak ground velocity and displacement, Arias intensity and relative significant duration, Bulletin of Earthquake Engineering, 10(5), 1339-1356. DOI: 10.1007/s10518-012-9359-6.

Douglas, J., Aochi, H. (2008), A survey of techniques for predicting earthquake ground motions for engineering purposes, Surveys in Geophysics, 29(3), 187-220. DOI 10.1007/s10712-008-9046-y.

Faccioli, E., Anastasopoulos, I., Callerio, A., Gazetas, G. (2008), Fault rupture-foundation interaction: selected case histories, Bulletin of Earthquake Engineering, 6(4), 557-583. DOI:10.1007/s10518-008-9089-y

Fotopoulou, S., Pitilakis, K. (2012), Vulnerability assessment of reinforced concrete buildings subjected to seismically triggered slow-moving earth slides, Landslides, DOI: 10.1007/s10346-012-0345-5.

Fotopoulou, S., Pitilakis, K. (2013), Fragility curves for reinforced concrete buildings to seismically triggered slow-moving slides, Soil Dynamics and Earthquake Engineering, 48, 143-161.

Galli, P., Galadini, F. (2001), Surface faulting of archeological relics. A review of case histories from the Dead Sea to the Alps, Tectonophysics, 335(3), 291-312.

Gallipoli, M. R., Bianca, M., Mucciarelli, M., Parolai, S., Picozzi, M. (2013), Topographic versus stratigraphic amplification: mismatch between code provisions and observations during the L'Aquila (Italy, 2009) sequence, Bulletin of Earthquake Engineering, 11(5), 1325-1336, doi: 10.1007/s10518-013-9446-3.

Garini, E., Gazetas, G. (2013), Damage potential of near-fault records: sliding displacement against conventional intensity measures, Bulletin of Earthquake Engineering, 11(2), 455-480.

Garini, E., Gazetas, G., Anastasopoulos, I. (2011), Asymmetric 'Newmark' sliding caused by motions containing severe 'directivity' and 'fling' pulses, Géotechnique, 61 (9), 753-756.

Gazetas, G., Loli, M., Anastasopoulos, I. (2014), Effects of permanent ground displacements due to near fault conditions on the seismic performance of masonry structures, Bulletin of Earthquake Engineering, this issue. 
Gazetas G. (2012), Some presumptions on the nature of base excitation may erroneously affect the response of strongly inelastic systems, Proceedings of the $15^{\text {th }}$ World Conference on Earthquake Engineering (WCEE), Lisbon, Portugal.

Gazetas, G., Garini, E., Anastasopoulos, I. (2009), Effects of near-fault ground shaking on sliding systems, Journal of Geotechnical Engineering, ASCE, 135 (12), 1906-1921.

Gehl, P., Seyedi, D.M., Douglas, J. (2013), Vector-valued fragility functions for seismic risk evaluation, Bulletin of Earthquake Engineering, 11(2), 365-384, DOI: 10.1007/s10518-012-9402-7.

Gelagoti, F., Kourkoulis, R., Anastasopoulos, I., Gazetas, G. (2012), Nonlinear dimensional analysis of trapezoidal valleys subjected to vertically propagating SV waves, Bulletin of Seismological Society of America, 102 (3), 199-1017.

Gelagoti, F., Kourkoulis, R., Anastasopoulos, I., Tazoh, T., Gazetas, G. (2010), Seismic wave propagation in a very soft alluvial valley: Sensitivity to ground motion "details" and soil nonlinearity, generation of parasitic vertical component, Bulletin of the Seismological Society of America, 100 (6), 3035-3054.

Goda, K., Atkinson, G.M. (2009), Probabilistic characterization of spatially correlated response spectra for earthquakes in Japan, Bulletin of the Seismological Society of America, 99(5), 3003-3020.

Hancock, J., Bommer, J. J. (2005), The effective number of cycles of earthquake ground motion, Earthquake Engineering and Structural Dynamics, 34, 637-664. doi: 10.1002/eqe.437.

Housner, G. W. (1959), Behavior of structures during earthquakes. Journal of the Engineering Mechanics Division, ASCE, 85(EM14), 109-129.

Jayaram, N., Baker, J. W. (2009), Correlation model for spatially distributed ground motion intensities, Earthquake Engineering and Structural Dynamics, 38(15), 1687-1708.

Karakhanian, A.S., Trifonov, V.G., Ivanova, T.P., Avagyan, A., Rukieh, M., Minini, H., Dodonov, A.E., Bachmanov, D.M. (2008), Seismic deformation in the St. Simeon Monasteries (Qal'at Sim'an), Northwestern Syria, Tectonophysics, 453 (1-4) 122-147.

Lagomarsino, S., Cattari, S. (2014), PERPETUATE guidelines for seismic performance-based assessment of cultural heritage masonry structures, Bulletin of Earthquake Engineering, this issue.

Lagomarsino, S., Modaressi, H., Pitilakis, K., Bosjlikov, V., Calderini, C., D’Ayala, D., Benouar, D., Cattari, S. (2010), PERPETUATE Project: the proposal of a performance-based approach to earthquake protection of cultural heritage, Advanced Materials Research, vol. 133-134, 1119-1124.

Lagomarsino, S., Abbas, N., Calderini, C., Cattari, S., Rossi, M., Ginanni Corradini, R., Marghella, G., Mattolin, F., Piovanello, V. (2011), Classification of cultural heritage assets and seismic damage variables for the identification of performance levels, Proc. of Structural Repairs and Maintenance of Heritage Architecture conference (STREMAH), 697-708, WIT Press, ISSN 1743-3509.

Loli, M., Bransby, M. F., Anastasopoulos, I., Gazetas, G. (2010), Interaction of caisson foundations with a seismically rupturing normal fault: Centrifuge testing versus numerical simulation, Geotechnique, 62(1), 29-43.

Miranda, E., Bertero, V. V. (1994), Evaluation of strength reduction factors for earthquake-resistant design, Earthquake Spectra, 10(2), 357-379.

Negulescu, C., Foerster, E. (2010), Parametric studies and quantitative assessment of the vulnerability of a RC frame building exposed to differential settlements, Natural Hazards and Earth System Sciences, 10(9), 17811792, doi:10.5194/nhess-10-1781-2010.

Oliveira, C. S. (2003), Seismic vulnerability of historical constructions: A contribution, Bulletin of Earthquake Engineering, 1(1), 37-82, 2003.

Pace, B., Albarello, D., Boncio, P., Dolce, M., Galli, P., Messina, P., Peruzza, L., Sabetta, F., Sanò, T., Visini, F. (2011), Predicted ground motion after the L'Aquila 2009 earthquake (Italy, $\mathrm{M}_{\mathrm{w}} 6.3$ ): input spectra for seismic microzoning, Bulletin of Earthquake Engineering, 9(1), 199-230, doi: 10.1007/s10518-010-9238-y.

Paolucci, R., Smerzini, C. (2008), Earthquake-induced transient ground strains from dense seismic networks, Earthquake Spectra, 24(2), 453-470, doi: 10.1193/1.2923923.

Pitilakis, K. (2004), Site Effects, Recent Advances in Earthquake Geotechnical Engineering and Microzonation, Ed. A. Ansal, Springer Netherlands, 139-197. 
Pitilakis, D., Clouteau, D. (2010), Equivalent linear substructure approximation of soil-foundation-structure 678 interaction: model presentation and validation. Bulletin of Earthquake Engineering, 8(2), 257-282. 679 doi:10.1007/s10518-009-9128-3.

680 Pitilakis, D., Karatzetzou, A. (2014), Impedance functions of flexible foundations to assess soil-foundation681 structure interaction in masonry monumental buildings, Bulletin of Earthquake Engineering, this issue.

682 Pitilakis, K., Riga, E., Anastasiadis, A. (2012), Design spectra and amplification factors for Eurocode 8, Bulletin 683 of Earthquake Engineering, 10(5), 1377-1400, DOI: 10.1007/s10518-012-9367-6.

684 Pitilakis, K., Riga, E., Anastasiadis, A. (2013a), New code site classification, amplification factors and 685 normalized response spectra based on a worldwide ground-motion database, Bulletin of Earthquake Engineering, 686 11(4), 925-966, DOI: 10.1007/s10518-013-9429-4

687 Pitilakis, K., Riga, E., Anastasiadis, A. (2013b), Erratum to: New code site classification, amplification factors 688 and normalized response spectra based on a worldwide ground-motion database, Bulletin of Earthquake 689 Engineering, 11(4), 967, DOI: 10.1007/s10518-013-9440-9.

690 Pitilakis, D., Moderessi-Farahmand-Razavi, A., Clouteau, D. (2013c), Equivalent-linear dynamic impedance 691 functions of surface foundations, Journal of Geotechnical and Geoenvironmental Engineering. 139(7), 1130692 1139, doi: 10.1061/(ASCE)GT.1943-5606.0000829.

693 Priestley, M. J. N., Calvi, G. M., Kowalsky, M. J. (2007), Displacement-based seismic design of structures, 694 IUSS Press, Pavia 721.

695 Rathje, E. M., Faraj, F., Russell, S., Bray, J. D. (2004), Empirical relationships for frequency content parameters 696 of earthquake ground motions, Earthquake Spectra, 20(1), 119-144.

697 Seyedi, D.M., Gehl, P., Douglas, J., Davenne, L., Mezher, N., Ghavamian, S. (2010), Development of seismic 698 fragility surfaces for reinforced concrete buildings by means of nonlinear time-history analysis, Earthquake 699 Engineering and Structural Dynamics, 39, 91-108, DOI:10.1002/eqe.939.

700 Toh, J. C. W., Pender, M. J. (2008), Earthquake performance and permanent displacements of shallow 701 foundations, Proceedings of New Zealand Society for Earthquake Engineering Conference, Paper Number 40. 